\title{
Políticas de Defesa da Concorrência e de Regulação Econômica: as Deficiências do Sistema Brasileiro de Defesa da Concorrência
}

\author{
José Matias-Pereira
}

\section{ResUMO}

É essencial, numa economia de mercado como a brasileira, que o governo possa contar com dois importantes instrumentos - que interagem e se complementam -, para garantir o crescimento econômico: a legislação antitruste e a política de regulação econômica. Nesse sentido, este artigo apoiado na denominada Nova Economia Institucional (Williamson, 1975, 1985, 1996; North, 1984, 1997; Olson, 1996; Stiglitz, 1990) -, tem o objetivo de retratar em linhas gerais a política e o sistema de defesa da concorrência no Brasil, bem como avaliar se as decisões do Conselho Administrativo de Defesa Econômica (CADE), a partir da abertura da economia brasileira nos anos noventa, estão contribuindo para o fortalecimento institucional do sistema de defesa da concorrência no Brasil, com destaque para os atos de concentração examinados pós-1994. Concluímos que, o sistema de defesa da concorrência no Brasil necessita de maior celeridade na apreciação de determinados atos, e aperfeiçoar o mecanismo de coordenação dos órgãos do sistema, para consolidar-se institucionalmente no Brasil.

Palavras-chave: defesa da concorrência; mercado concorrencial; ato de concentração; Brasil.

\begin{abstract}
In a market economy as the Brazilian, who the government can count on two important instruments - that they interact and if they complement -, to guarantee the economic growth: the antitrust legislation and the politics of economic regulation. In this direction, this article - supported in called New Institutional Economy (Williamson, 1975, 1985, 1996; North, 1984, 1997; Olson, 1996; Stiglitz, 1990) -, the objective has to portray in general lines the politics and the system of free market defense in Brazil, as well as evaluating if the decisions of the Board of directors of CADE, from the opening of the Brazilian economy in the Nineties, are contributing for the institutional fortify of the system of free market defense in Brazil, with prominence for the examined acts of concentration after-1994. We conclude that, the system of free market defense in Brazil needs bigger rapidity in the appreciation of determined acts, and to perfect the mechanism of coordination of the agencies of the system, to consolidate itself institutional in Brazil.
\end{abstract}

Key words: free market defense; competition; competition market; concentration act; Brazil. 


\section{INTRODUÇÃO}

A relevância das políticas de defesa da concorrência no Brasil aparece com maior nitidez com as mudanças do papel do Estado, no início dos anos noventa, em decorrência do avanço nas privatizações das empresas estatais, afastando-se de sua função de Estado empresário (Farina \& Azevedo, 2001). É oportuno lembrar que, nas décadas de setenta e oitenta, havia sido consolidada uma economia essencialmente apoiada nas grandes empresas estatais. Esta situação permitiu que o Estado se transformasse num fornecedor privilegiado de bens e serviços para o consumidor ou na referência de garantia de produtos e serviços pela iniciativa privada. Dessa forma, o Estado empresário consolida-se e, em muitos casos, se sobrepõe à própria administração pública direta. Com a dificuldade de exercer um maior controle de preços, em decorrência da consolidação do fenômeno da formação dos conglomerados estatais, o Estado brasileiro passou a incentivar as formações empresariais cartelizadas. A reconhecida importância das decisões que eram adotadas pela Comissão Interministerial de Preços (CIP), nesse período, decorre dessas disfunções econômicas, que geraram uma degeneração no sistema concorrencial do país. Verifica-se, assim, que a economia brasileira se encontrava apoiava, no final da década de oitenta, nas grandes empresas estatais e nas estruturas cartelizadas (Matias-Pereira, 2004a).

O Cade, com a relevância dada pelo Estado para a sua função de regulador, ampliou significativamente a sua dimensão. A abertura da economia e a promulgação da Lei $\mathrm{n}^{\circ} .8 .884$, de 1994 criam as condições para garantir a defesa da concorrência no país (Salgado, 1997). Procura-se evitar, assim, que as empresas estabelecidas abusem de suas posições dominantes, impondo restrições à competição nos mercados em que atuam, ou ainda incrementem seu poder de mercado por meio de alianças ou fusões com empresas concorrentes. Assim, as políticas de defesa da concorrência, além de coibir que as barreiras suprimidas pelo governo sejam recompostas pelos agentes com elevado nível de poder econômico, propõe-se a criar uma cultura concorrencial entre produtores e consumidores, cujas normas de competição passam a ser necessárias para garantir a própria existência do mercado (Considera \& Araújo, 2002).

Observa-se que a regulação do mercado, especialmente em setores em que a estrutura do livre mercado apresenta elevado grau de concentração - visto que concentrar é restringir o espaço de mercado - é uma condição indispensável garantir um adequado ambiente concorrencial (Vaz, 1993). A presença do Estado na organização da economia aumentou significativamente no mundo atual com 
os danos causados pelas grandes concentrações ao mercado, notadamente diante da possibilidade de ocorrer um dano potencial para as outras empresas que estavam atuando no citado mercado. A concentração deve ser vista como uma ação que, mesmo quando não inviabiliza a concorrência, altera o nível de competição, prejudicando em última instância o consumidor. Registre-se que, a regulação de setores específicos na economia tem como propósito corrigir eventuais falhas de mercado (Le Moal, 1979).

É perceptível que o mercado se apresenta como instrumento essencial para atender as demandas materiais do ser humano, atuando como poupador de recursos e tempo, na medida em que permite a troca entre pessoas de uma maneira impessoal. Os mercados são instituições humanas que funcionam apoiadas num conjunto de regras sociais que variam no tempo e no espaço. Assim, o mercado para cumprir a função, como as demais instituições humanas, necessita de que determinadas normas sejam preservadas, entre as quais destacamos duas: a liberdade de concorrer no mercado e a autonomia de escolha do consumidor. Para que ocorra o funcionamento adequado do mercado é preciso que o Estado disponha de instituições de salvaguarda sólidas na área de defesa da concorrência (Matias-Pereira, 2003, 2005).

\section{Tradição em Defesa da Concorrência nos Países em Desenvolvimento}

Sendo a concorrência a regra do mercado torna-se possível sustentar que a ela deve ser creditada a elevação do nível de competitividade e de qualidade dos bens e serviços ofertados pelas empresas ao mercado consumidor. As empresas para sobreviver nesse ambiente hostil, conforme argumenta Schumpeter no seu estudo Theory of Economic Development (1912), tende a criar, em muitos casos, algum tipo de restrição à atuação e de entrada de novos concorrentes no mercado. Ao Estado cabe a responsabilidade de atuar como garantidor da cidadania econômica (Organização para a Cooperação e o Desenvolvimento Econômico [OCDE], 1992).

Observa-se, em particular nos países em desenvolvimento, com pouca tradição em defesa da concorrência, as interferências políticas e empresariais para rever as decisões dos órgãos de defesa da concorrência. Esse fenômeno também se verifica no Brasil, onde as decisões do Cade não são aceitas pacificamente pelas lideranças políticas e empresariais dos Estados afetados pelas decisões do órgão. Para Matias-Pereira (2004a) essas pressões que questionam a decisão e a própria existência do Cade podem ser creditadas, entre outros aspectos, à carência de uma cultura no campo da defesa da concorrência no Brasil. Isso é agravado pelo desconhecimento das lideranças políticas e empresariais de que o objetivo maior 
da defesa da concorrência é definir se determinada operação entre agentes econômicos ou a prática restritiva à concorrência estão produzindo efeitos indesejáveis ao mercado relevante analisado.

Essas constatações demonstram que o Sistema Brasileiro de Defesa da Concorrência - SBDC encontra-se parcialmente frágil institucionalmente, o que se vem refletindo na sua capacidade de assegurar a aplicação das regras de concorrência no país, em conformidade com o princípio da economia de mercado e da livre concorrência (North, 1990). Diante dessas evidências formulamos as seguintes perguntas:

- A aplicação da legislação antitruste no Brasil, traduzidas nas decisões adotadas no âmbito do CADE, no período 1994 a 2004, em particular nos exames dos atos de concentração, estão contribuindo para a consolidação institucional do sistema de defesa da concorrência no Brasil?

. Como são percebidas pela sociedade, em particular pelos usuários, as deficiências e fragilidades do Sistema Brasileiro de Defesa da Concorrência no Brasil?

Assim, tendo como ponto de partida a pergunta acima, temos como objetivo principal neste artigo, contribuir para o aprofundamento da compreensão dos aspectos relacionados as duas classes de políticas econômicas essenciais para apoiar o crescimento econômico: a regulação econômica e a defesa da concorrência, com ênfase nesta última; bem como analisar se as decisões do Cade - a partir da promulgação da legislação antitruste de 1994 -, estão contribuindo para o fortalecimento institucional do Sistema Brasileiro de Defesa da Concorrência (SBDC). Vamos debater, ainda, as questões conceituais e teóricas mais relevantes nessas áreas e analisar como a teoria econômica está sendo utilizada para elevar a consistência das análises dos casos que envolvem a defesa da concorrência no Brasil, e de forma específica, sobre os atos de concentração (Ministério da Fazenda [MF], 2001).

\section{Conceitos Básicos Relacionados à Defesa da Concorrência}

Torna-se relevante, metodologicamente, conceituar os principais termos utilizados na discussão do tema defesa da concorrência. Esses termos foram apropriados do Glossário Básico de Defesa da Concorrência (Ministério da Fazenda [MF], 2004).

Ordem econômica deve ser entendida como um conjunto de princípios estabelecidos pela Constituição Federal do Brasil em seu título VII (artigos 170 a 192), e que tem por objetivos fixar os parâmetros da atividade econômica, coordenando a atuação dos diversos sujeitos que põe em prática aquela mesma atividade. A predominância de uma economia social de mercado, que valoriza o 
capitalismo democrático, enfatiza o direito de propriedade individual, e sua consequiência inarredável: o princípio da liberdade de iniciativa, como fatores indispensáveis para o progresso e o impulso da atividade econômica. Defendemse, porém, ao mesmo tempo, os princípios da função social da propriedade, da livre concorrência, de respeito aos direitos dos consumidores e dos trabalhadores. Propugna-se pela presença regulamentadora do Estado, predominantemente, mas também por uma presença atuante nos casos em que a lei específica como necessários (MF, 2004).

Agente econômico deve ser entendido como qualquer pessoa física ou jurídica (empresa privada ou pública, com fins lucrativos ou não, indústria, comércio, profissional liberal, etc.) que participa, independentemente, como sujeito ativo na atividade econômica. Regulação econômica refere-se a políticas em que o Governo controla preços e/ou decide que empresas participam no mercado.

Defesa da concorrência refere-se a políticas que definem determinados comportamentos das empresas como sendo ilegais, por prejudicarem os consumidores e/ou diminuírem o bem-estar social.

Custos de transação são os gastos associados às transações entre agentes econômicos, de modo geral, que não se expressam nos preços acordados entre as partes, sendo exemplo o custo de elaborar e aplicar um contrato (MF, 2004).

Controle de concentrações é uma das vertentes de atuação do sistema brasileiro de defesa da concorrência (SBDC). O Cade, balizado pelos pareceres da Secretaria de Direito Econômico (SDE) e da Secretaria de Acompanhamento Econômico (SEAE), aprecia se determinada concentração de empresas pode causar efeitos danosos à concorrência. Os atos de concentração têm, potencialmente, efeitos negativos e positivos sobre o bem-estar econômico. Os efeitos negativos decorrem de um eventual exercício de poder de mercado pela empresa concentrada - aumento de preços, fundamentalmente - enquanto os efeitos positivos derivam de economias de escala, de escopo, de redução de custos de transação, entre outros, que podem proporcionar vantagens competitivas para as empresas participantes. A esse respeito, veja a definição legal no $\S 3^{\circ}$ do artigo 54 da Lei n. ${ }^{\circ}$ 8.884/94 (MF, 2004).

Conglomeração é a concentração que envolve agentes econômicos distintos, que ofertam produtos ou serviços distintos que podem ou não ser complementares entre si, mas que, certamente, não fazem parte da mesma cadeia produtiva. Genericamente, uma conglomeração é saudável à competição, pois significa a entrada de uma empresa em determinado mercado de produto ou serviço. No entanto uma conglomeração pode ter efeitos nocivos à concorrência, quando houver complementaridade entre os produtos ou serviços envolvidos (MF, 2004). 
Concentração horizontal é aquela concentração que envolve agentes econômicos distintos e competidores entre si, que ofertam o mesmo produto ou serviço em determinado mercado relevante. A concentração (ou integração) vertical é aquela que envolve agentes econômicos distintos, que ofertam produtos ou serviços distintos, e que fazem parte da mesma cadeia produtiva (MF, 2004).

Condutas oportunistas são condutas verificadas quando uma parte envolvida em determinado contrato procura aproveitar-se, às custas da outra parte, do processo de renegociação do referido contrato (MF, 2004).

\section{Enfoques Teóricos das Políticas de Defesa da Concorrência}

A política de defesa da concorrência está tradicionalmente apoiada na teoria de organização industrial (Matias-Pereira \& Kruglianskas, 2005). Essa teoria foi desenvolvida a partir dos anos 50 pela Escola de Harvard, em que a estrutura da empresa, traduzida no número de produtores e compradores, diferenciação do produto, barreiras à entrada, estruturas de custos, integração vertical e diversificação, determinaria a sua conduta. Ou seja, na definição de políticas de preços, pesquisa e desenvolvimento (P\&D), estratégia e investimento, e esta, o seu desempenho - alocação eficiente dos recursos, satisfação aos consumidores, progresso técnico, equidade de renda, entre outros. Desta forma, toda concentração de mercado seria ineficiente. Esse enfoque criou o denominado paradigma estrutura-conduta-desempenho.

$\mathrm{Na}$ atualidade, a literatura econômica vem dando destaque a uma nova visão, que incorporou nas suas análises o conceito de eficiência. Assim, da análise per $s e$, ou seja, restrição a qualquer ato de concentração, evoluiu-se para a utilização da regra da razoabilidade, na qual um ato de concentração pode ser acatado, desde que ele implique em ganhos de eficiência. A partir dessa percepção, buscamos apresentar, a seguir, as proposições normativas mais relevantes deste enfoque, que procura levar em consideração a eficiência que pode reduzir os efeitos negativos provocados por configurações de mercado mais concentrado.

\section{Instituições Econômicas e a Teoria da Nova Economia Institucional}

Argumenta Kwoka e White (1999) que a revolução na política antitruste americana, nas últimas duas décadas, é resultado da aplicação da teoria econômica no debate judicial dessa área. Essa constatação ajuda a explicar a razão da existência de um consenso entre os economistas de que, se há algum corpo de leis que deve sua existência à teoria econômica, certamente é o caso das leis de 
concorrência. A teoria aplicada ao estudo das organizações, focalizando a análise microeconômica, que foi desenvolvida por Williamson (1985) no seu livro The Economic Institutions of Capitalism - apoiado nas contribuições de Coase (1937), Arrow (1985), Simon (1972) e de Macneil (1974, 1978) -, utiliza dois pressupostos comportamentais básicos: o da racionalidade limitada de Simon (1972) e o seu corolário, os contratos incompletos que, associados ao pressuposto do oportunismo, fornecem as bases para a análise das formas de governança das organizações.

É importante, também, para este estudo, ressaltar a relevância da farta literatura que mostra as evidências teóricas e empíricas sobre as vantagens do livre mercado para atingir maiores taxas de crescimento econômico. Entre esses estudos destacamos, por exemplo, (1991; 1996); Friedman (1962); Hayek (1978); e North (1997).

Este artigo está apoiado na teoria do neoinstitucionalismo econômico. Essa teoria, no amplo conjunto de temas e enfoques que cuida, incorpora os atritos sociais, os conflitos distributivos e as estruturas de poder que surgem no mundo real, quando se relacionam à economia e às instituições, por meio de contratos, regulações, direitos de propriedade e, em geral, leis que regulamentam essas questões. O neoinstitucionalismo, é relevante ressaltar, enfoca as estruturas de poder desde uma dupla perspectiva: a organização e o controle do sistema econômico e o processo jurídico, ou seja, o nexo entre marco jurídico-processo econômico, que é o processo central que organiza a estrutura da relação jurídicogoverno-política-economia.

$\mathrm{Na}$ análise da evolução das principais relações e influências das escolas do pensamento econômico iremos constatar que os antecedentes do neoinstitucionalismo são bastante remotos, visto que vamos localizar as suas origens nos estudos dos economistas clássicos, no historicismo alemão, na escola austríaca e no marxismo, com destaque para Adam Smith, John Stuart Mill e Karl Marx. Privilegiaremos, também, em nossa análise, distintos autores, como por exemplo, Kwoka e White, 1999; Posner, 1998; Macneil, 1974 e 1978; Kahn, 1988; Dahl e Lindblom, 1992; Coase, 1937, 1988; Ross, 1973 e 1993; Kaplan, 1980; Farina, 1990, 1996; Matias-Pereira, 2004a; Pondé, Fagundes e Possas, 1997, Possas, Fagundes e Pondé, 1995; 1998a, 1998b; Sullivan e Harrison, 1988; Dosi, Teece e Winter, 1992. Em particular, daremos especial atenção às vertentes que compõem a denominada Nova Economia Institucional: a economia dos custos de transação de Williamson $(1975,1985,1996)$; a teoria de evolução institucional de North, 1984 e 1997; além dos autores da vertente que cuida das instituições e desempenho econômico, como, por exemplo, Olson (1996), North (1997), e Stiglitz (1990), por entenderem que as instituições jogam um papel decisivo na dinâmica e no desenvolvimento de qualquer sistema 
econômico. Por meio delas é possível explicar o êxito ou fracasso, o crescimento ou a estagnação de um sistema socioeconômico. Assim, as instituições (formais e informais) definem o marco de restrições legais e extralegais (econômicas, sociais e culturais etc.) no meio dos quais os indivíduos atuam, se organizam e promovem intercâmbios.

\section{Economia e Prática Antitruste no Mundo}

A economia e a prática antitruste no mundo, nas duas últimas décadas, passaram por uma série de transformações que introduziram, de forma crescente, argumentos de eficiência econômica, sobretudo de caráter produtivo, como justificativa para atos de concentração e determinadas condutas empresariais (Kwoka \& White, 1999). Como resultado, os órgãos de defesa da concorrência em diversos países passaram a avaliar não somente os efeitos anticompetitivos, como na antiga tradição, mas também os potenciais impactos em termos de ganhos de eficiência econômica no julgamento de condutas horizontais e verticais, fusões, aquisições e joint ventures entre empresas (Brault, 1995).

A justificativa teórica mais relevante, no campo da economia, em que pese não ser a única, para a regulação encontra-se no argumento do monopólio natural. As mudanças tecnológicas, por sua vez, reduziram a importância das economias de escala na determinação de tamanhos mínimos eficientes de planta, desafiando a existência de um significativo trade off entre eficiência produtiva e alocativa, rationale econômica da regulação dos monopólios naturais. Assim, a preocupação de caracterizar tecnicamente a existência de monopólio natural em determinado setor deixou de ser relevante. O que passou a ser relevante foi o esforço de se comprovar se os ganhos de eficiência e custos derivados da escala monopolística são suficientes para compensar os custos e riscos da regulação.

\section{Regulação Setorial, Defesa da Concorrência e Parâmetros Regulatórios do Estado}

Dentre as funções desempenhadas pelo Estado, destaca-se a regulação setorial e a defesa da concorrência nas economias de mercado. Essa atividade é de fundamental importância para as empresas e para a economia em geral. Muitas empresas atuam em mercados sujeitos à regulação setorial específica, com implicações decisivas na sua atividade, que podem ir desde as formas de organização empresarial às estratégias de preços e investimentos (Kahn, 1988). As empresas, em outros casos, decorrentes da posição relevante que detêm nos mercados em que atuam, necessitam dispensar especial atenção às regras de defesa da concorrência, em áreas como de preços, descontos, compras de bens 
e serviços, bem como nas operações de concentração em que se envolvem. A regulação e a defesa da concorrência, dessa forma, são indispensáveis para uma economia de mercado saudável e competitiva, com repercussões em todos os setores de atividade econômica.

A atividade de regulação se apresenta como um grande desafio para a Administração Pública, pois está relacionada com a própria modernização do Estado na atualidade, por meio das mudanças na forma e no conteúdo das suas relações com as empresas e o público em geral (Considera \& Albuquerque, 2001). É um processo que envolve a análise e o diagnóstico dos problemas, o estudo de possibilidades de atuação e a fundamentação das decisões tomadas, em matérias de grande exigência técnica. Assim, torna-se evidente que a formação de competências nas áreas de economia da regulação e da concorrência representa um fator indispensável na atividade empresarial e em diferentes áreas da Administração Pública.

A maneira e a forma peculiar pelas quais as políticas e os sistemas de defesa da concorrência enfrentam essas questões se altera de país para país, embora várias semelhanças possam ser observadas, sobretudo no que diz respeito ao objetivo básico da legislação antitruste de exercer algum tipo de controle sobre atos de concentração e sobre as condutas das empresas que detêm poder de mercado (Brault, 1995). Percebe-se que, para cada área de aplicação das políticas de defesa da concorrência, determinadas linhas orientadoras no que se refere à concepção econômica que as baliza. A esse respeito, veja o trabalho de Posner (1998), Economic Analysis of Law, que aborda a análise econômica do direito.

\section{Critérios de Análise dos Atos de Concentração}

A presunção de que uma operação gere acréscimo de poder de mercado e efeitos anti-competitivos, na linha das proposições do enfoque estruturalista de organização industrial, decorre da avaliação de que o grau de concentração do mercado relevante, seguindo as proposições do enfoque estruturalista de organização industrial, é alto e será elevado ainda mais pela operação em análise, em contexto no qual a intensidade da concorrência potencial é baixa, ainda que outros elementos também possam ser levados em conta (Ponde et al., 1997). Assim, na análise antitruste de atos de concentração de natureza horizontal utilizase o seguinte critério: (i) estimativas das participações das empresas no mercado relevante; (ii) avaliação do nível das barreiras à entrada; e (iii) exame das eficiências econômicas geradas pela operação. As operações que implicam aumento considerável do grau de concentração em mercados caracterizados por elevado nível de barreiras à entrada e baixo dinamismo tecnológico, por não apresentarem 
evidências da geração de ganhos de eficiência produtiva significativos, não costumam ser autorizadas pelas autoridades antitrustes.

Quanto à medição do aumento do nível de concentração, verifica-se que a delimitação das dimensões do mercado é feita por um instrumento conceitual especifico, a análise econômica no âmbito da defesa da concorrência, incorporando simultaneamente os aspectos da elasticidade da oferta e da demanda. Dessa forma, o mercado relevante de uma operação é definido como aquele no qual, em uma situação hipotética, um eventual monopolista poderia exercer seu poder de mercado, elevando preços e auferindo lucros extraordinários (Possas, 1996; Possas et al., 1997, 1998a).

O nível de concentração é mensurado por indicadores tais como a participação de mercado das quatro maiores firmas (CR4) ou o índice Herfindahl-Hirschman (HHI), calculado por meio da soma dos quadrados dos market shares individuais das firmas participantes no mercado relevante. Em relação à concorrência potencial, a análise das condições de entrada é usualmente realizada levando-se em conta as quatro fontes de barreiras à instalação de novos concorrentes propostas originalmente por Bain (1956). Essas fontes de barreiras englobam a diferenciação de produtos, as vantagens absolutas de custo, as economias de escala e as exigências de investimentos iniciais elevados.

Procura-se, por fim, avaliar em que medida as eficiências econômicas - cujas bases têm origem, em geral, nas visões tradicionais e nas características da tecnologia, como as economias de escala e de escopo, eventualmente geradas pela operação -, podem contrabalançar os efeitos anticompetitivos. Esses efeitos são derivados do aumento de poder de mercado, pressuposto, por sua vez, a partir do incremento do grau de concentração e manifesto num suposto futuro aumento de preços que reduz o excedente do consumidor.

As fusões ou aquisições conglomeradas, isto é, realizadas entre empresas situadas em mercados relevantes distintos, são vistas como potencialmente anticompetitivas à luz das teorias da concorrência potencial, em suas duas vertentes, a teoria do entrante potencial percebido (perceived potential entrant) e a do entrante potencial efetivo (actual potential entrant). $\mathrm{Na}$ primeira delas, os possíveis efeitos anticompetitivos de uma operação de aquisição, fusão ou associação entre uma empresa já instalada no mercado e um entrante potencial resulta de uma redução da ameaça de entrada que estaria impedindo uma elevação de preços e margens. Já na segunda, supõe-se que um processo de entrada já estaria em vias de ser desencadeado pelo competidor potencial participante da operação, de modo que esta evita que uma estrutura de mercado mais desconcentrada - e supostamente mais competitiva - se configure no futuro próximo (Kaplan, 1980; Ross, 1993). 


\section{Indicadores de Avaliação do Sistema de Defesa da Concorrência do Brasil}

Diante das limitações das avaliações nacionais na área de defesa da concorrência no Brasil, iremos utilizar a pesquisa denominada Rating Enforcement: Our annual ranking of the world's 27 senior competition regimes, 2003, publicada em 2004 pela Global Competition Review (www.globalcompetitionreview.com/news/frontpage.cfm) para apoiar as nossas argumentações na parte das conclusões. Trata-se de uma classificação, em que pesem as eventuais restrições, especialmente dos órgãos que se encontram numa posição desfavorável, que está apoiada em parâmetros objetivos e entrevistas feitas com advogados de várias partes do mundo. Os advogados e economistas entrevistados opinam sobre as agências de seus e de outros países, ou seja, a avaliação brasileira foi feita por advogados e economistas brasileiros e de alguns de outros países. Esse método, por si só, pode resultar em algumas distorções, visto que é possível que os especialistas de outras nacionalidades escondam as falhas das agências de seus respectivos países.

A Global Competition Review (GCR) para realizar a sua pesquisa busca obter dados sobre as agências: número de funcionários, orçamento e número total de casos (dividindo-os em atos de concentração, cartéis, abusos de posição dominante e outros). Com vista a uma possível comparação entre a estrutura das agências norte-americanas e do Brasil, podemos observar que a FTC conta com mais de mil funcionários para examinar menos de 300 casos por ano, dos quais cerca de 220 são atos de concentração. Já o DoJ tem 400 funcionários para cerca de 280 casos anualmente, dos quais 175 são atos de concentração. Os EUA aparecem no topo do ranking da GCR em 2003, com 4,5 estrelas.

Ressalte-se que, as duas agências norte-americanas (a Federal Trade Commission - FTC e o of Justice - DoJ) são classificadas separadamente (Department of Justice - Federal Trade Commission, 2003). A comparação desses dados, sem considerar os orçamentos, evidencia a fragilidade do Brasil, cujo SBDC atua significativamente desaparelhado, em termos de recursos orçamentários e humanos. Esses dados explicam por que o resultado da pesquisa colocou o Brasil numa posição tão desconfortável.

Feitas essas observações, torna-se possível destacar os principais aspectos identificados na pesquisa divulgada pela GCR, que colocou o Sistema de Defesa da Concorrência do Brasil com uma menção de 2,5 estrelas num máximo de 5, na $23^{\mathrm{a}}$ posição, no conjunto das 26 agências de defesa da concorrência avaliadas (Matias-Pereira, 2004a). 
a) Aspectos positivos apontados pela pesquisa. A pesquisa da GCR registra como relevantes a adoção de diversas ações pelos SBDC em 2003, orientadas para melhorar o combate aos cartéis e o julgamento de fusões e aquisições, apesar da pouca estrutura que o governo lhes concede. Destaca-se na avaliação as providências inéditas de combate aos cartéis, feita pela Secretaria de Direito Econômico, como ações de busca de apreensão de provas na sede de empresas e sindicatos suspeitos e a assinatura do primeiro acordo de leniência do Brasil (no qual a empresa confessa participação num cartel e consegue redução de pena); início de um procedimento simplificado para a análise de fusões e aquisições; e a criação de um site que permite o acesso às informações dos três órgãos do sistema. Na avaliação também foi considerada a independência política nas agências brasileiras, que se mantiveram alheias a pressões políticas e empresariais. As autoridades, por sua vez, estão sendo vistas de maneira mais positiva pelo público pelas mudanças e mostraram disposição para reforçar a atuação.

b) Aspectos negativos apontados pela pesquisa. Entre os aspectos negativos, a pesquisa indica que a burocracia continua intensa. O Brasil é visto como um país que pede informações em excesso às empresas antes de julgar as fusões e aquisições. A evolução do sistema brasileiro de defesa da concorrência continua a sofrer pelas questões irrelevantes feitas às empresas e pelo quadro jovem e inexperiente dos funcionários. A pesquisa observa que a criação de um plano de carreiras no Cade dará mais estrutura e melhores salários, e é vista como necessária para a evolução do sistema de defesa da concorrência do país.

\section{Matriz das Principais Decisões Adotadas pelo CADE Pós-1994}

Após a descrição dos principais aspectos apontados pela pesquisa divulgada pela Global Competition Review, procederemos a seguir, de forma sucinta, com vista a reforçar as nossas argumentações, uma análise sobre o nível de consistência das principais decisões do Cade após a promulgação da Lei Antitruste, em 1994. A referida análise foi baseada no exame do instrumental teórico contido nos votos dos conselheiros daquele órgão, em particular os votos dos conselheiros-relatores, conforme consta da matriz apresentada no Quadro 1 , a seguir. 


\section{Quadro 1: Matriz das Principais Decisões Antitrustes Adotadas pelo CADE - 1994 a 2004}

\begin{tabular}{|c|c|c|c|c|}
\hline Ato de Concentração & Partes envolvidas & Assunto & $\begin{array}{c}\text { Nível } \\
\text { sofisticação } \\
\text { do voto }\end{array}$ & Decisão \\
\hline $\begin{array}{c}\text { Caso Gerdau/Pains } \\
\text { Ato de Concentração no } \\
16 / 1994\end{array}$ & $\begin{array}{c}\text { Siderúrgica Pains } \\
\text { Cabomat } \\
\text { Gerdau }\end{array}$ & $\begin{array}{l}\text { Aquisição da Siderúrgica } \\
\text { Pains pela Gerdau. }\end{array}$ & Média & $\begin{array}{l}\text { Proibição do negócio. O } \\
\text { Ministério da Justiça pediu } \\
\text { a revisão da decisão e o } \\
\text { Cade determinou a venda } \\
\text { da Pains a Cabomat. }\end{array}$ \\
\hline $\begin{array}{c}\text { Caso Kolynos/Colgate } \\
\text { Ato de Concentração no } \\
27 / 1994\end{array}$ & $\begin{array}{l}\text { Kolynos } \\
\text { Colgate }\end{array}$ & $\begin{array}{l}\text { Aquisição da Kolynos pela } \\
\text { Colgate. }\end{array}$ & Média & $\begin{array}{l}\text { Suspensão da marca } \\
\text { Kolynos por quatro anos. } \\
\text { Criação da marca Sorriso. }\end{array}$ \\
\hline \multirow{3}{*}{$\begin{array}{c}\text { Caso Biobrás } \\
\text { Ato de Concentração } \\
\text { 08012.007861/2001-81 }\end{array}$} & Novo Nordisk Holding do Brasil & \multirow{3}{*}{$\begin{array}{l}\text { Aquisição pela Novo Nordisk } \\
\text { Holding do Brasil Ltda de } \\
27,4 \% \text { do capital total da } \\
\text { Biobrás }\end{array}$} & \multirow{3}{*}{ Média } & \multirow{3}{*}{ Assinatura de APRO* } \\
\hline & Biopart Ltda & & & \\
\hline & BNDES & & & \\
\hline \multirow{2}{*}{$\begin{array}{c}\text { Caso Nestlé } \\
\text { Ato de Concentração } \\
\text { 08012.001697/2002-89 }\end{array}$} & Chocolates Garoto S/A & \multirow{2}{*}{$\begin{array}{l}\text { Aquisação pela Nestlé Brasil } \\
\text { Ltda da totalidade do capital } \\
\text { da Chocolates Garoto S/A }\end{array}$} & \multirow[b]{2}{*}{ Média } & \multirow{2}{*}{$\begin{array}{c}\text { Desfavorável à compra. Em } \\
\text { andamento processo de } \\
\text { venda da Garoto pela } \\
\text { Nestlé. }\end{array}$} \\
\hline & Nestlé Brasil Ltda & & & \\
\hline \multirow{2}{*}{$\begin{array}{c}\text { Caso Varig e TAM } \\
\text { Ato de Concentração } \\
08012.001291 / 2003-87\end{array}$} & TAM Linhas Aéreas & \multirow{2}{*}{$\begin{array}{l}\text { Acordo de "code share" entre } \\
\text { as empresas e possível } \\
\text { constituição de nova empresa }\end{array}$} & \multirow[b]{2}{*}{ Média } & \multirow{2}{*}{$\begin{array}{c}\text { Favorável ao "code-share". } \\
\text { Empresas sob investigação } \\
\text { por possível formação de } \\
\text { cartel. }\end{array}$} \\
\hline & Varig S/A & & & \\
\hline \multirow{2}{*}{$\begin{array}{c}\text { Caso Companhia Brasileira } \\
\text { de Distribuição } \\
\text { Ato de Concentração } \\
08012.0004897 / 02-93 \\
\end{array}$} & $\begin{array}{c}\text { Companhia Brasileira de } \\
\text { Distribuição - Pão de Açúcar }\end{array}$ & \multirow{2}{*}{$\begin{array}{c}\text { Compra e posterior venda da } \\
\text { Rede Sé de Supermercados } \\
\text { pela CBD* }\end{array}$} & \multirow{2}{*}{ Alta } & \multirow{2}{*}{$\begin{array}{c}\text { Favorável em parte à CBD. } \\
\text { Companhia autorizada a } \\
\text { utilizar suas bandeiras nas } \\
\text { lojas da Rede Sé }\end{array}$} \\
\hline & Rede Sé Supermercados & & & \\
\hline \multirow{3}{*}{$\begin{array}{c}\text { Caso Bayer } \\
\text { Ato de Concentração } \\
\mathbf{0 8 1 2 . 0 0 7 1 7 6 / 2 0 0 2 - 3 5}\end{array}$} & Reckitt Benckiser Brasil & \multirow{3}{*}{$\begin{array}{l}\text { Concentração de mercado } \\
\text { pela S.C. Johnson \& Son Inc. } \\
\text { e Bayer AG. }\end{array}$} & \multirow{3}{*}{ Média } & \multirow{3}{*}{ Desfavorável à Reckitt. } \\
\hline & S.C. Johnson \& Son Inc & & & \\
\hline & Bayer AG & & & \\
\hline \multirow{3}{*}{$\begin{array}{c}\text { Caso CSN/Usiminas//Cosipa } \\
\text { Ato de Concentração n } \\
08012.004166 / 98-9\end{array}$} & $\begin{array}{l}\text { Companhia Siderúrgica } \\
\text { Nacional - CSN } \\
\end{array}$ & \multirow{3}{*}{$\begin{array}{l}\text { Acusação de cartel por } \\
\text { aumentos nos preços do aço } \\
\text { realizado por CSN, Usiminas } \\
\text { e Cosipa. }\end{array}$} & \multirow{3}{*}{ Média } & \multirow{3}{*}{$\begin{array}{c}\text { Siderúrgicas multadas em } \\
\text { valor igual a } 1 \% \text { do } \\
\text { faturamento. Estas } \\
\text { recorreram ao Poder } \\
\text { Judiciário para não pagar a } \\
\text { multa. } \\
\end{array}$} \\
\hline & Usiminas & & & \\
\hline & Cosipa & & & \\
\hline \multirow{3}{*}{$\begin{array}{l}\text { Ato de Concentração } \\
08012.005846 / 99-12\end{array}$} & Brahma & \multirow{3}{*}{ Fusão da Brahma-Antarctica. } & \multirow{3}{*}{ Média } & \multirow{3}{*}{$\begin{array}{l}\text { Venda da marca Bavária. } \\
\text { A Molson comprou a } \\
\text { Bavária e, adquiriu em } \\
\text { seguida a Kaiser. }\end{array}$} \\
\hline & Molson & & & \\
\hline & Antarctica & & & \\
\hline
\end{tabular}

Fonte: Conselho Administrativo de Defesa Econômica (CADE). (1995, 2003, 2004): www.cade.gov.br *APRO - Acordo de Preservação de Reversibilidade da Operação (Medida cautelar). Veja o art. $8^{\circ}$ da Resolução do CADE nº. 28, de 24 de julho de 2002: www.cade.gov.br

A matriz permitir-nos uma melhor visualização da forma como o Cade avaliou e decidiu os atos de concentração selecionados. Registre-se que apenas em um caso - o que envolveu a Companhia Brasileira de Distribuição - se utilizou cálculos sofisticados. Nesse caso houve a presença de pesquisas de concorrência, realizadas por empresas externas, que fizeram o levantamento a respeito do market share das empresas envolvidas e a análise concorrencial visando apurar os preços praticados pela outra organização do processo. A análise do caso Pão de Açúcar - Companhia Brasileira de Distribuição - realizou também uma minuciosa avaliação dos prejuízos sofridos pela empresa CBD - Pão de Açúcar com a 
compra da Rede Sé, explicitados nos gráficos apresentados pela companhia. Nessa avaliação ficou constatado o enorme empenho do Grupo Pão de Açúcar em produzir informações consistentes sobre o citado ato de concentração, e dessa forma obter ganho de causa junto ao Cade.

Observa-se que nessas análises foi utilizado um adequado instrumental teórico, tanto na área microeconômica como na do direito antitruste (Oliveira, 2001). Os debates acirrados em torno de todos esses casos, que ficaram restritos aos espaços políticos, empresariais e acadêmicos, e que foram explicitados pela mídia, aumentam as evidências de que a sociedade não tem recebido as informações sobre o tema em nível satisfatório. Quando examinamos os reflexos para a sociedade das decisões adotadas no âmbito daquele órgão, do ponto de vista administrativo, jurídico e político, torna-se perceptível que as regras na área da defesa da concorrência, analisada sob a ótica da mídia, são desconhecidas pela grande maioria da população do país.

Constata-se que o governo federal não se tem mostrado capaz de informar adequadamente a sociedade da importância das decisões adotadas pelo sistema de defesa da concorrência para o desenvolvimento econômico do país. Apesar dessa deficiência, fica evidenciado que a cultura da concorrência se materializa com decisões dessa natureza, conforme se evidencia na pesquisa realizada pela Global Competition Review junto aos profissionais que atuam na área.

Os principais atores nesse contexto, especialmente os empresários, reclamam sistematicamente que são prejudicados pela burocracia, e o longo tempo despendido nessas análises. Isso reforça a constatação da pesquisa realizada pela Global Competition Review em 2002 e 2003 sobre a necessidade de o Estado disponibilizar os recursos necessários, tanto em estrutura como em recursos humanos, para que o órgão possa cumprir adequadamente a sua função, incluindo a adoção de um sistema de notificação prévia das operações de fusões (Franco Neto et al., 2004). Fica evidenciado, dessa forma, que o Brasil ainda necessita evoluir significativamente no campo da defesa da concorrência. Assim, é fundamental para o perfeito funcionamento da economia que os atos e as decisões sob a responsabilidade dos órgãos que integram o sistema de defesa da concorrência passem a ter maior celeridade.

\section{Defesa da Concorrência, Regulação e Proteção ao Consumidor: Síntese das Entrevistas Qualitativas}

Na busca de aprofundar a análise sobre o Sistema Brasileiro de Defesa da 
Concorrência do Brasil (SBDC), realizamos diversas entrevistas qualitativas, num total de 6 (seis), com distintos especialistas na área. Os temas abordados nestas entrevistas foram: defesa da concorrência, regulação e proteção ao consumidor. Apresentamos, a seguir, de forma sintética, os argumentos utilizados por esses atores nessas entrevistas:

\section{Quadro 2: Quadro Síntese das Entrevistas Qualitativas}

\section{Percepção sobre as falhas e deficiências no Sistema de Defesa da Concorrência no Brasil}

. A nova realidade econômica e a promulgação da Lei no 8.884 , de 1994, criaram as condições para colocar na agenda nacional a relevância das políticas públicas de defesa da concorrência e do consumidor no Brasil.

. Existe uma percepção de que ocorre uma excessiva morosidade dos processos de investigação e no julgamento feitos pela Sde, Seae e Cade. Essas dificuldades são observadas, em especial, na questão da análise prévia e na necessidade de redução do que deve ou não ser submetido ao Sistema de Defesa da Concorrência.

. A concorrência será tanto maior quanto mais livre for o comércio entre os países e quanto menor for a interferência do Estado no processo econômico.

. O controle efetivo de condutas anticompetitivas está vinculado a dois aspectos: a conscientização da sociedade sobre a importância da livre concorrência para garantir preços justos e a existência de um arcabouço jurídico-institucional que viabilize o cumprimento dessa vontade social.

\section{As Funções de Defesa da Concorrência, Regulação e Proteção ao Consumidor:}

. Observada a natureza das funções de defesa da concorrência, regulação e proteção ao consumidor, verifica-se que os objetivos da função regulatória são mais amplos: cuidam da regulação técnica, sanitária, ambiental, econômica, além de fiscalização e ação preventiva. Envolve a substituição dos mecanismos de mercado, além de ser anterior à consumação das transações de mercado.

. O método adotado na proteção ao consumidor também envolve a substituição dos mecanismos de mercado, mas seus objetivos são mais restritos e sua atuação ocorre posteriormente à realização dos negócios.

. Os objetivos da defesa da concorrência também são restritos, mas para sua consecução emprega-se um método que prioriza a utilização dos mecanismos de mercado.

- A agência Antitruste preocupa-se com a defesa dos mecanismos de mercado (expost) e as agências de Regulação com a substituição dos mecanismos de mercado (exante).

. No seu conjunto, todas as três atividades são justificadas sob a ótica da teoria econômica pela presença de falhas de mercado, sendo que a regulação e a defesa do consumidor têm origem em problemas de poder de mercado, informação assimétrica, existência de bens públicos ou de externalidades. 


\title{
(continuação) \\ Quadro 2: Quadro Síntese das Entrevistas Qualitativas
}

\begin{abstract}
A Relevância do Direito de Defesa da Concorrência:
. O direito de defesa da concorrência - entendido como um conjunto de princípios e normas jurídicas capazes de regular o poder econômico, bem como suas manifestações nos mercados definidos como relevantes, está situado, tanto histórico quanto analiticamente, na interconexão de três vetores distintos: a política econômica, a dogmática do direito econômico e a teoria econômica.

. Os sistemas jurídicos e políticos reconhecem o poder econômico como um fenômeno naturalmente alcançável e, por isso, juridicamente permitido.
\end{abstract}

\section{Relação entre Regulação Setorial e Defesa da Concorrência:}

. A convivência entre as autoridades de defesa da concorrência e das agências regulatórias deve ser a mais convergente possível. A interface que existe entre o sistema de defesa da concorrência e as agências reguladoras seja priorizada. As normas editadas pelas agências reguladoras, em boa parte, não levam em consideração o impacto dessas medidas na concorrência entre os agentes econômicos, e os benefícios que isso pode causar para o consumidor final.

. Como regulação e defesa da concorrência derivam de leis aplicadas por autoridades distintas, sem relação hierárquica ou institucional entre si, não é possível almejar, em que pese o princípio constitucional da livre concorrência, que a Lei e a Autoridade Antitruste se sobreponha às leis setoriais.

\section{As ações de Defesa da Concorrência e do Consumidor:}

. O sistema de defesa do consumidor brasileiro é baseado em um modelo descentralizado de órgãos e entidades governamentais e não-governamentais. A defesa da concorrência, por se tratar de questão de abrangência nacional, requer uma única análise, a qual é centralizada nas três entidades federais que compõem o SBDC (Seae, Sde e Cade).

- Verifica-se que a defesa da concorrência e a do consumidor guardam alguns aspectos em comum. Isso, entretanto, não é suficiente para justificar a unificação da proteção à concorrência e da defesa do consumidor em uma mesma entidade estatal. Essa proteção conjunta poderia propiciar medidas conflituosas, visto que o bem-estar do consumidor é apenas um dos objetivos visados pela defesa da concorrência. 


\section{(conclusão)}

\section{Quadro 2: Quadro Síntese das Entrevistas Qualitativas}

\section{Recomendações para modernizar o Modelo Regulatório Brasileiro:}

. Não houve consenso como irá ocorrer a inserção entre a agência antritruste e as agências reguladoras setoriais. Esses órgãos, por possuírem natureza e objetivos distintos, cumprem funções complementares para a constituição de um marco regulatório adequado aos interesses da sociedade.

. Deve-se evitar a banalização do conceito de agência regulatória. Para as agências classicamente regulatórias defendem o formato de órgão colegiado - no qual as decisões de substância são tomadas por maioria -, para evitar as tentativas de pressão por parte de interesses dos agentes regulados, bem como das pressões oriundas do governo, por interesses eventualmente contrariados.

- A aplicação adequada da lei tende a gerar segurança nos investidores privados. Busca-se restringir, dessa forma, os riscos de captura, que dificultam a consolidação do modelo de Estado regulador da atividade econômica.

. O Brasil vive um momento histórico de amadurecimento de sua política de concorrência. Isso requer uma nova configuração do SBDC que, além de buscar uma clareza maior do sistema, seja priorizado o controle do planejamento antitruste, no sentido de compatibilizar a política de concorrência com a de desenvolvimento.

Obs. As entrevistas tiveram como base, entre outros, os depoimentos dos especialistas que participaram do "Seminário sobre os Dez Anos da Lei de Defesa da Concorrência", promovido pela Câmara Britânica de Comércio e Indústria no Brasil (Britcham), em especial: Gesner de Oliveira, Bárbara Rosenberg, Luciano Coutinho e Daniel Goldberg, realizado em São Paulo, 14 de setembro de $2004^{(1)}$.

\section{Conclusões}

Observa-se que o esquema protecionista, que prevaleceu nos anos oitenta e início de noventa, isolava as empresas nacionais da concorrência estrangeira. Isso explica parcialmente por que o tema "defesa da concorrência" não tenha não tenha recebido uma atenção especial dos governos e dos diferentes agentes econômicos. A ausência de antecedentes sobre a aplicação da legislação de concorrência e, conseqüientemente, a falta de desenvolvimento jurisprudencial e doutrinário sobre o tema é evidente no caso brasileiro (Considera \& Corrêa, 2002). Por sua vez, a carência de uma cultura na área de defesa da concorrência no Brasil explica em parte as pressões e a resistência de setores políticos e empresariais às decisões do Cade (Matias-Pereira, 2004a).

É inegável que o adequado funcionamento da economia depende que o Estado 
exerça de maneira eficiente, eficaz e efetivo o seu papel de orientar e tutelar a liberdade de concorrência e proibir, restringir ou sancionar condutas que atentem de forma ilegítima contra esta (Posner, 1998). Assim, é responsabilidade do Estado dar maior celeridade e tornar mais seletivos os critérios que definem quais atos de concentração precisam ser submetidos à aprovação dos órgãos de defesa da concorrência.

Está evidenciado que o Brasil, apesar das deficiências assinaladas, destaca-se entre os países em desenvolvimento, na administração e aplicação das regras de defesa da concorrência. Isto é uma realização relevante, especialmente em país que tem ampla história de intervenção governamental na economia e onde a cultura da concorrência é fraca, tanto na comunidade empresarial como junto à população. Na medida em que o processo de globalização da economia avança, o Brasil tem que lidar com diversos casos de fusões internacionais que envolvem grandes empresas multinacionais, nos mais distintos setores, como fertilizantes, chocolates, cervejas, aço e saúde, entre outras. Está evidenciado (vide Quadro 1), que os casos apreciados pelo Cade - em particular os atos de concentração tem sido tratados de acordo com os princípios da melhor prática identificada na área de defesa da concorrência. Estas práticas, entretanto, necessitam ser constantemente aperfeiçoadas, em particular nas questões que envolvem as agências reguladoras ${ }^{(2)}$.

A adoção de medidas para aumentar a articulação entre os órgãos de defesa da concorrência com os demais órgãos de governo nos três níveis, em particular com as agências reguladoras de serviços públicos, se apresenta como uma medida essencial para aumentar a concorrência e a eliminação de distorções que existem nestes setores. Isso exige uma crescente convergência na interface entre as autoridades de defesa da concorrência e das agências regulatórias. Observa-se que, as normas editadas pelas agências reguladoras, em boa parte, não levam em consideração o impacto dessas medidas na concorrência entre os agentes econômicos, e os benefícios que isso pode causar para o consumidor final $^{(3)}$.

Ressaltamos, por fim, a importância da busca permanente do fortalecimento da legislação antitruste e da gestão das políticas de defesa da concorrência e de regulação econômica, por serem indispensáveis no processo de crescimento econômico do país.

Artigo recebido em 23.04.2004. Aprovado em 03.02.2006. 


\section{NOTAS}

${ }^{1}$ Para um maior aprofundamento sobre o assunto, veja os estudos de Considera, C.; Corrêa, P. The political economy of antitrust policy in Brazil - from price control to competition policy. In: Hawk, B. E. (Ed.). 2001 Annual Proceedings of the Fordham University School of Law, International Antitrust Law and Policy. NY: Juris Publishing, 2002, p. 533-68; Salgado, L. H. Agências Regulatórias na Experiência Brasileira: um panorama do atual desenho institucional, Texto para Discussão, $\mathrm{n}^{\circ}$ 941, IPEA, março de 2003; e, Oliveira, G., Werneck, B.; Machado, E. L., Agências Reguladoras: A Experiência Internacional e a Avaliação da Proposta de Lei Geral Brasileira, CNI, Brasília, 2004.

${ }^{2}$ A reestruturação da defesa da concorrência no Brasil, mediante o redesenho institucional do Sistema Brasileiro de Defesa da Concorrência (SBDC), atualmente regulado pela Lei no .8 .884 , de 1994, está sendo proposta pelo governo federal por meio do Projeto de Lei (PL) nº. 5.877, recepcionado em 12 de setembro de 2005 pela Câmara dos Deputados.

${ }^{3}$ O Relatório "Lei e Política de Concorrência no Brasil. Uma revisão pelos pares" (OCDE, 2005), contou com a colaboração com o Banco Interamericano de Desenvolvimento (BID). Foi elaborado por Jay Shaffer. O Relatório traz 22 sugestões de mudanças, algumas direcionadas diretamente ao CADE e outras que podem ser implementadas por outros órgãos do governo, além dos que compõem o SBDC. O processo de elaboração do peer review incluiu pedidos de informações às autoridades brasileiras - não só da área de defesa da concorrência mas também de órgãos reguladores e outros ministérios - e entrevistas com membros da comunidade acadêmica, advogados, economistas, consultores, jornalistas, além de entidades civis ligadas ao setor produtivo e à área de concorrência.

\section{Referencias Bibliográficas}

Arrow, K. J. (1985).

The economics of agency. In J. Pratt, R. Zeckhauser (Eds.). Principals and agents: the structure of business (pp. 37-51). Boston: Harvard Business School Press.

Bain, J. (1956).

Barriers to new competition. Cambridge, Mass: Harvard University Press.

Barro, R. J. (1991). Economic Growth in a Cross Section of Countries. The Quarterly Journal of Economics, 106(2), 407- 443.
Barro, R. J. (1996, March).

"Democracy And Growth." Journal of Economic Growth, 1(1), 1-27.

Brault, D. (1995).

Droit de la concurrence comparé: vers un Ordre Concurrentiel Mundial? Colection droit des affaires de l'entreprise. Série: Recherches. Paris: Ed. Economica.

Coase, R. H. (1937, November).

The nature of the firm. Economica, 4(16), 386-405.

Coase, R. H. (1988).

The firm, the market and the law (pp. 33-55). Chicago: The University of Chicago Press. 
Conselho Administrativo de Defesa Econômica (1995).

Decisão do ato de concentração que analisou a compra da Siderúrgica Pains pela Gerdau. Brasília: Cade/MJ. Recuperado em 13 janeiro, 2005, de http://www.cade.org.br

Conselho Administrativo de Defesa Econômica (2003).

Relatórios das atividades do Cadê, período 1996/2003. Brasília: Cade/MJ. Recuperado em 27 janeiro, 2005, de http://www.cade.org.br

Conselho Administrativo de Defesa Econômica (2004).

Decisão do ato de concentração que analisou a compra da Empresa de Chocolates Garoto pela Nestlé. Brasília: Cade/MJ. Recuperado em 25 janeiro, 2005, de http:// www.cade.org.br

Considera, C. M., \&

Albuquerque, K. (2001, August 10).

The relationship between competition policy and regulation Brazilian Economy [Working Paper]. (pp. 1-14). Ministério da Fazenda/SEAE.

Considera, C. M., \&

Araújo, M. T. (2002).

Competition advocacy in Brazil recent development. Brasília: Ministério da Fazenda/SEAE, pp. 112. Recuperado em 12 janeiro, 2004, de http://www.fazenda.gov.br

Considera, C. M., \&

Corrêa, P. (2002).

The political economy of antitrust policy in Brazil - from price control to competition policy. In B. E. Hawk (Ed.). 2001 Annual Proceedings Of the Fordham University School of Law,
International Antitrust Law and Policy. (pp. 533-68). New York: Juris Publishing.

Dahl, R., \&

Lindblom, C. (1992).

Politics, Economics and Welfare (2nd ed.). London: Transaction Publishers.

Department of Justice - Federal Trade Commission (2003).

Horizontal Merger Guidelines. Washington-DC: Department of Justice and Federal Trade Commission.

Dosi, G.,

Teece, D., \&

Winter, S. (1992).

Towards a theory of corporate coherence: preliminary remarks. In G. Dosi, R. Gianetti, \& P. Toninelli (Eds.). Technology and Enterprise in a Historical Perspective. (pp. 185-211). Oxford: Clarendon Press.

Farina, E. M. M. Q. (1990).

Política antitruste: a experiência brasileira. Anais do Encontro Nacional de Economia, Brasília, DF., 18, 455-474.

Farina, E. M. M. Q. (1996, agosto).

Política industrial e política antitruste: uma proposta de conciliação. Revista do IBRAC, 3(8), 34-64.

Farina, E. M. M. Q., \&

Azevedo, P.F. (2001).

Política Industrial e Defesa da Concorrência: considerações sobre a experiência brasileira nos anos 90 . Textos de Economia, Rio de Janeiro, 2(1), 513-547. 
Franco Neto, A. A. M.,

Campilongo, C. F., \&

Macedo, R. P., Jr. (2004, março 03).

Nestlé sem Garoto. Folha de São Paulo, p. A3.

Friedman, M. (1962).

Capitalism and freedom. (p. 202).

Chicago: University of Chicago Press.

Global Competition Review (2004).

The 2003 Handbook of Competition Enforcement Agencies. Rating Enforcement - our annual ranking of the world's 27 senior competition regimes. London: Global Competition Review. Recuperado em 12 dezembro, 2005, de http:// www.globalcompetitionreview.com/ bookstore/sample.cfm.

Kahn,A. E. (1988).

The economics of regulation: principles and institutions, Cambridge: MIT Press.

Kaplan, L. (1980).

Potential competition and section 7 of the Clayton Act. The Antitrust Bulletin, 25(2), 297-326.

Kwoka, J., \&

White, L. (Eds.). (1999).

The antitrust revolution-economics, competition and policy (3rd. ed.). Oxford: Oxford University Press.

Le Moal, R. (1979).

Droit de concurrence. Paris: Ed. Economica.

Macneil, I. R. (1974).

The many futures of contracts, Southern California Law Review, 47(1), 691-816.
Macneil, I. R. (1978).

Contracts: adjustment of long-term economic relations udder classical, neoclassical, and relational contract law. Northwestern University Law Review, 72 (1), 854-905.

Matias-Pereira, J. (2003).

Economia Brasileira. São Paulo: Editora Atlas.

Matias-Pereira, J. (2004a, Mayo).

Políticas públicas de defesa do consumidor e da concorrência no Brasil: uma avaliação do processo de consolidação institucional do sistema brasileiro de defesa da concorrência. Revista Académica de Economía, 1(24), 1-16. Málaga: Universidad de Málaga. Recuperado em 21 setembro, 2005, de http://www.eumed.net/ cursecon/ecolat/br/jmp-cons.doc

Matias-Pereira, J. (2005).

Política de Defesa da Concorrência e de Regulação Econômica: as deficiências do Sistema Brasileiro de Defesa da Concorrência. Anais do Encontro Nacional dos Programas de Pós-Graduação em Administração, Brasília, DF., 29.

Matias-Pereira, J., \&

Kruglianskas, I. (2005, julho/dezembro). Gestão de Inovação: A Lei de inovação tecnológica como ferramenta de apoio às políticas industrial e tecnológica do Brasil. Revista de Administração de Empresas, 4(2), Art. 18, 01-21. Recuperado em 21 dezembro, 2005, de http://www.rae.com.br/eletronica 
Ministério da Fazenda (2004). Glossário de termos econômicos. Brasília: Seae/MF. Recuperado em 05 janeiro, 2005, de http:// www.fazenda.gov.br

Ministério da Fazenda (2001, agosto $1^{\circ}$ ). Guia para análise econômica de atos de concentração, Portaria Conjunta. Brasília: MF/SEAE/SDE, $\mathrm{n}^{\circ} .50$.

North, D. (1984).

Estructura y cambio en la historia económica. Madrid: Alianza Universidad.

North, D. (1990).

A transaction cost Theory of politics. Papers 144, Washington St. Louis School of Business and Political Economy.

North, D. (1997). Institutions, institutional change and economic performance (7th ed.). Cambridge: Cambridge University Press.

Organização para a Cooperação e o Desenvolvimento Econômico (1992). Regulatory reform, privatization and competition policy. Recuperado em 12 janeiro, 2005, de http:// www.oecd.org

Oliveira, G. (2001). Concorrência - panorama no Brasil e no mundo. São Paulo: Saraiva.
Olson, M. (1996, March).

The Economics of Autocracy and Majority Rule: the invisible hand and the use of force, The Journal of Economic Literature, 34(1), 72-96.

Pondé, J. L.,

Fagundes, J. \&

Possas, M. (1997, julho/dezembro).

Custos de Transação Política de Defesa da Concorrência. Revista de Economia Contemporânea, 1(2), 115135.

Posner, R. (1998).

Economic analysis of law (5th ed.). New York: Aspen Publishers.

Possas, M. L. (1996, maio).

Os conceitos de mercado relevante e de poder de mercado no âmbito da defesa da concorrência. Revista do IBRAC, 3(5), 1-19.

Possas, M. L.,

Fagundes, J., \&

Pondé, J. (1995).

Política antitruste: um enfoque Schumpeteriano. Anais do Encontro Nacional de Economia, Salvador, BA, 23 .

Possas, M. L., Fagundes, J., \& Pondé, J. (1997).

Custos de transação e políticas de defesa da concorrência. Revista de Economia Contemporânea, 2(1), 915, Rio de Janeiro: UFRJ/IE. Recuperado em 28 janeiro, 2005, de http://www.ie.ufrj.br/grc/artigos.htm 
Possas, M. L.,

Fagundes, J., \&

Pondé, J. (1998a).

Defesa da concorrência e regulação na transição de monopólios naturais para estruturas oligopolistas. Relatório de Pesquisa, IPEA, Rio de Janeiro: UFRJ. Recuperado em 23 dezembro, 2005, de http:// www.ie.ufrj.br/grc/pdfs/ defesa_da_concorrencia\%20e_ regulacao_de_setores_de infra_estrutura_em_transicao.pdf

Possas, M. L.,

Fagundes, J., \&

Pondé, J. (1998b).

Custos de transação e políticas de defesa da concorrência. Revista de Economia Contemporânea, 2, 9-15. Rio de Janeiro: UFRJ/IE. Recuperado em 28 janeiro, 2005, de http:// www.ie.ufrj.br/grc/artigos.htm

Ross, Stephen F. (1973, May).

The economic theory of agency: the principal's problem. American Economic Review, 63(2), 134-139.

Ross, Stephen F. (1993).

Principles of antitrust law. Westbury, NY: The Foundation Press.

Salgado, L. H. (1997).

A economia política da ação antitruste. São Paulo: Singular.
Schumpeter, J.A. (1912)

The Theory of Economic Development. With an Introduction by John E. Elliott. New Brunswick, NJ: Transaction Publishers.

Simon, H. A. (1972).

Theories of bounded rationality. In C. B. Mcguire, \& R. Radner, (Eds.). Decision and organization. New York: American Elsevier.

Stiglitz, J. (1990).

The economic role of the State, (2nd. ed.). Oxford: Basil Blackweel.

Sullivan, E., \&

Harrison, J. (1988).

Understanding antitrust and its economic implications. New York: Matthew Bender \& Co.

Vaz, I. (1993).

Direito econômico da concorrência. Rio de Janeiro: Forense.

Williamson, O.E. (1975).

Market and hierarchies: analysis and antitrust implications. New York: The Free Press.

Williamson, O. E. (1985).

The Economic institutions of capitalism. New York: The Free Press.

Williamson, O. E. (1996).

The mechanisms of governance.

Oxford: Oxford University Press. 